\title{
Barbiturate und energieliefernder Stoffwechsel in der hämoglobinfrei durchströmten Leber der Ratte
}

\author{
Herrn Professor Dr. Joachim Kühnau zum 60. Geburtstag \\ Von R. Scholz, F. Schwarz ${ }^{1}$ ) und Th. Bücher \\ Aus dem Physiologisch-Chemischen Institut der Universität München (Direktor: Prof. Dr. Dr. Th. Bücher)
}

(Eingegangen am 8. April 1966)

\begin{abstract}
Die Wirkung von Amytal und anderen Barbituraten auf die isolierte, hämoglobinfrei perfundierte Rattenleber wurde mit Hilfe von amperometrischer Sauerstoff bestimmung, Fluorometrie und Metabolitanalysen im Perfusat untersucht. Unabhängig von den Perfusionsbedingungen beträgt die maximale Atmungshemmung durch Amytal $66 \%$ der Atmung im stationären Zustand. Derivate mit gleicher oder ähnlicher Seitenkette am C-A tom 5 der Barbitursäure, Amytal, Nembutal und Pentothal, hemmen die Atmung in gleichem Ausmaße. Evipan und Luminal zeigen eine geringere, Veronal eine nur sehr schwache Atmungshemmung. Die Sensibilität der Atmung gegenüber Amytal, gekennzeichnet durch die Konzentration für halbmaximalen Effekt, ist abhängig von der Stoffwechselsituation der I.eber. Die höchste Sensibilität wurde bei Lebern mit vorwiegendem Koblenhydratkatabolismus, die geringste bei Umsatz von Ölsäure gemessen.

Die Ketogenese wird unter Amytaleinwirkung verstärkt. Bei bereits vorliegendem Fettsäurekatabolismus erreicht die Produktion an $\beta$-Hydroxybutyrat Werte um $30 \mu \mathrm{Mol} / \mathrm{Std}$./g. Die unter diesen Bedingungen geringere Sensibilität der Atmung gegenüber Amytal kann durch eine vermehrte Einschleusung flavinspezifischer Wasserstoffpaare in das System der Atmungskette erklärt werden. - Oxybarbiturate steigern die durch reduzierte Pyridinnukleotide verursachte Oberflächenfluoreszenz der hämoglobinfreien Leber. Bei maximaler Amytalkonzentration wird ein Fluoreszenzanstieg von $80 \%$ des Anstieges bei Anoxie beobachtet. Eine Korrelation besteht zwischen Atmungshemmung und Fluoreszenzanstieg unter Amytaleinwirkung. Nur bei sehr geringen Amytalkonzentrationen steigt die Fluoreszenzintensität ohne entsprechende Atmungshemmung. - Die Barbituratwirkung auf Atmung und Fluoreszenz ist reversibel. Eine Ausnahme bildet das Thiobarbiturat Pentothal.

Amytal senkt das Redoxpotential des LDH-Systems von -230 auf $-247 \mathrm{mV}$ und das Redoxpotential des $\beta$ HOBDH-Systems von -268 auf $-289 \mathrm{mV}(3 \mathrm{mM})$. Bei glykogenhaltigen Lebern steigt die Lactatproduktion von \pm 20 auf $110 \mu \mathrm{Mol} / \mathrm{Std}$./g. Der halbmaximale Effekt wird bereits bei einer Amytalkonzentration von 0,25 mM erreicht. Die biosynthetischen Funktionen der Leber weisen eine unterschiedliche Amytalsensibilität auf. Die Glukoneogenese aus Alanin wird schon bei Konzentrationen zwischen 0,6 und $0,9 \mathrm{mM}$ vollständig gehemmt, bei denen die Harnstoffsynthese noch wenig beeinflußt ist. Ammoniumionen werden jedoch bei diesen Amytalkonzentrationen bereits vermehrt freigesetzt.
\end{abstract}

The effects of Amytal and other barbiturates on the isolated, hemoglobin-free, perfused rat liver were investigated using the amperometric measurement of oxygen tension, surface fluorometry and the analysis of metabolites in the perfusate. The steady state respiration is inhibited about 66 per cent by Amytal, independently of the experimental conditions. Amytal, Nembutal and Pentothal, which are characterised by similar side chains substituted at C-5 of the barbituric acid, exhibit an equal inhibition of respiration. The effects of Evipan and Luminal are smaller; the inhibition by Veronal is very weak. The sensitivity of respiration to Amytal, expressed as the concentration for the half maximal effect, depends on the metabolic state of the liver. Livers utilizing carbohydrate were found to be more sensitive than livers utilizing oleic acid.

Ketogenesis increases under the influence of Amytal. When Amytal is given to a liver utilizing fatty acids, the production of $\beta$-hydroxybutyrate amounts to about $30 \mu \mathrm{moles} / \mathrm{hr}$./g. The lower sensitivity of respiration to Amytal observed under these conditions is possibly due to an increased utilization of flavin-specific hydrogen. The surface fluorescence of the hemoglobin-free liver caused by reduced pyridine nucleotides is increased when hydroxybarbiturates are added to the perfusion fluid. A maximal concentration of Amytal causes an increase of fluorescence, which is about $80 \%$ of that observed in anoxia. A correlation exists between the inhibition of respiration and the increase of fluorescence by Amytal. Very small concentrations of Amytal, however, effect an increase of fluorescence without a corresponding inhibition of respiration. With respect to respiration and fluorescence, the effects of hydroxybarbiturates are reversible. In contrast, the effects of the thiobarbiturate, Pentothal, are irreversible.

The redox potential of the $\mathrm{LDH}$ system is reduced from -230 to $-247 \mathrm{mV}$ by Amytal. Similarly, the redox potential of the $\beta$-HOBDH-system is reduced from -268 to $-289 \mathrm{mV}(3 \mathrm{mM})$. In liver containing glycogen, the production of lactate increases from \pm 20 to $110 \mu \mathrm{moles} / \mathrm{hr} . / \mathrm{g}$. with Amytal, the concentration for half maximal effect being $0.25 \mathrm{mM}$.

Biosynthesis is variously influenced by Amytal. Gluconeogenesis from alanine is completely inhibited by concentrations between 0.6 and $0.9 \mathrm{mM}$, whereas the synthesis of urea is sligthly affacted by these concentrations. The excretion of ammonia, however, is increased at lower concentrations.

Die Wirkungen der Barbiturate als Inhibitoren des Gewebsstoffwechsels sind seit den grundlegenden Beobachtungen von QUASTEL im Jahre 1932 (1) in zahlreichen Arbeiten beschrieben worden (Übersicht bei 2-4). Die neueren Untersuchungen zellphysiologischer Richtung 1) Diese Arbeit enthält Teile der Dissertation von Frank SCHWARZ. betreffen vorwiegend Messungen an isolierten Mitochondrien (5-18). Sie geben Einblicke nicht nur in den Mechanismus der Barbituratwirkung, sondern auch in den organisatorischen Plan der Atmungskette.

Weitaus am häufigsten ist Amytal, das 5-Äthyl-5-isoamyl-Derivat der Barbitursäure, untersucht worden. Im Bereich der mitochondrialen Wasserstoff- und Elektro- 
nen-Übertragung hemmt es die an Diphosphopyridinnucleotid gebundenen Oxydationen $(9,11)$. In kleinen Konzentrationen, bei denen der Elektronenfluß der Atmungskette bereits entscheidend gehemmt ist, entkoppelt Amytal nicht die oxydative Phosphorylierung $(14,15)$. Dennoch steht seine Wirkung in gewissen, noch nicht geklärten Beziehungen zu den Reaktionen der energetischen Transformation, da sowohl Intensität als auch Qualität des Amytaleffektes vom Grad der energetischen Kopplung der Mitochondrien abhängen (16, 17, 18). Bei nichtphosphorylierenden Mitochondrien hemmt Amytal die Elektronenübertragung zwischen Flavoprotein und der Cytochrom b-Ubichinon-Region (10, $12,13)$. Dagegen ist bei enggekoppelten Mitochondrien, deren Atmungskette durch das Angebot an Phosphatacceptoren kontrolliert wird, der entsprechende crossover-point von der Sauerstoff- zur Substratseite des Flavoproteins hin verschoben. Ein Angriffspunkt von hoher Affinität ist demnach jene Seite der mitochondrialen DPNH-Oxydation, welche dem System der energetischen Transformation zugewandt ist (16).

Wegen der Reversibilität seiner Wirkungen ist Amytal zu einem oft verwendeten Hilfsmittel der Mitochondrienforschung geworden, nicht zuletzt, weil man mit seiner Hilfe in isolierten Mitochondrien, Zellen (19) und Geweben die Redoxmediatoren der Atmungskette oberhalb der Pyridinnucleotide in den oxydierten Zustand versetzen kann. Zu diesem Zweck haben wir in einer vorausgegangenen Untersuchung über den Status der Cytochrome im Parenchym der hämoglobinfrei durchströmten Leber Amytal verwendet (20-22). Die dabei gewonnenen Beobachtungen haben uns angeregt, die Messungen auf andere Parameter (Registrierung der Atmungsgröße und Oberflächenfluoreszenz, Messung des Austausches von Metaboliten mit der Perfusionsflüssigkeit) auszudehnen. Wegen ihres klinisch-chemischen und pharmakologischen Interesses wurden weitere Barbiturate in die Untersuchungen einbezogen. Das gewonnene Material gibt einen Einblick in die Interdependenzen mitochondrialer Funktionen innerhalb der Komplexität des Leberparenchyms.

\section{Methodik}

Hämoglobinfreie Leberperfusion

Die Technik und die besonderen Gegebenheiten, sowie die methodischen Möglichkeiten der hämoglobinfreien Perfusion einer isolierten Rattenleber wurden an anderer Stelle beschrieben $(20,22)$. Abbildung 1 zeigt das Perfusionssystem als Blockdiagramm. Es setzt sich, zusammen aus einem Oxygenator, Pumpen für den $\mathrm{Zu}-$ und Rückfluß, einem temperierten Gefäß für die Leber, sowie Platinelektroden zur Messung des Sauerstoffdrucks im Schlauchsystem vor und hinter der Leber. Die Apparatur ist für eine Perfusion sowohl im offenen als auch im rezirkulierenden System eingerichtet. Als Oxygenator dienten zunächst temperierte Säulen, in denen die Perfusionslösung mit Gasgemischen $\left(95 \% \mathrm{O}_{2}+5 \%\right.$ $\mathrm{CO}_{2}$, bzw. $95 \%$ Argon $+5 \% \mathrm{CO}_{2}$ ) durchperlt wurde. Später verwendeten wir für die Oxygenierung Zylinderoxygenatoren aus Kunststoff.

Perfusionslösung

Die Perfusionslösung besteht aus der isotonen Lösung eines Salzgemisches mit Zusatz von 7\% Dextran (mittleres Molekulargewicht 40000; "Rheomakrodex“, Fa. Knoll AG, Ludwigshafen) als

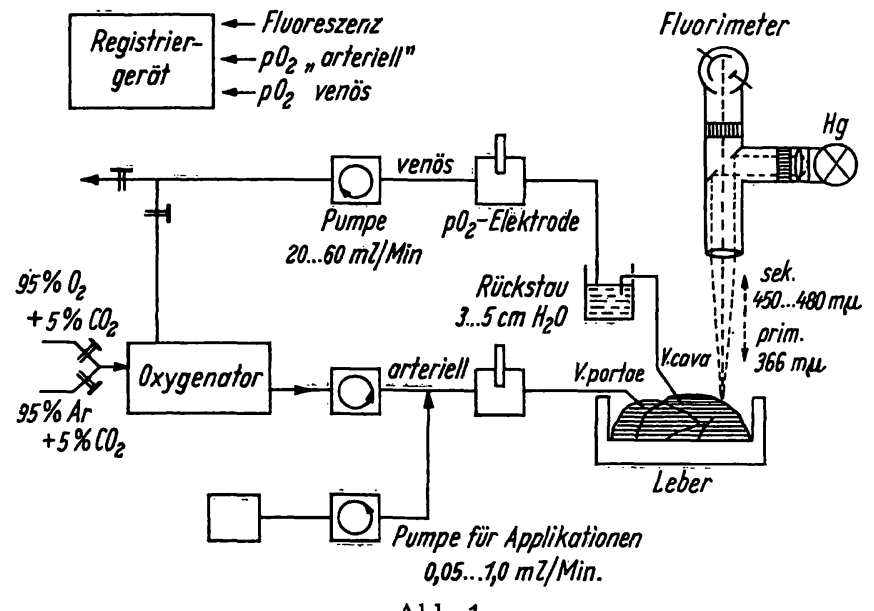

Abb. 1

Blockdiagramm eines Systems für hämoglobinfreie Durchströmung von Rattenlebern

onkotische Substanz. Das unter Standardbedingungen verwendete Medium A $(20,22)$ enthält zusätzlich Glukose $(5,5 \mathrm{mM})$, Lactat $(1,5 \mathrm{mM})$ und ein Gemisch aus 7 glukoplastischen Aminosäuren in den Konzentrationen, die für Rattenserum angegeben werden (23). Medium B, das in den Versuchen mit Lebern von gehungerten Ratten verwendet wird (Glukoneogenesebedingungen), enthält $6 \%$ Dextran, 1\% Albumin (Serumalbumin vom Rind, reinst, Behring-Werke, Marburg) und als Substrat lediglich Alanin (10 mM); $\mathrm{pH} 7,40$; Temperatur $36^{\circ}$.

\section{Oberflächenfluoreszenz}

Die Messung der Oberflächenfluoreszenz wurde entsprechend der von CHANCE angegebenen Methode (24) durchgeführt. Wir verwenden dazu ein Aufsichtsmikroskop („Ultrapak“, Fa. Leitz, Wetzlar), das wir mit einer wassergekühlten Quecksilberdampflampe (ST 40, Fa. Heraeus, Hanau), Glasfiltern und einem Photomultiplier (RCA 1 P 21) ausgerüstet baben. Die Primärstrahlung von $366 \mathrm{~m} \mu$ wird auf die Leberoberfläche gerichtet. Die im Lebergewebe bis zu einer Tiefe von $1-2 \mathrm{~mm}$ erregte blaue Fluoreszenz mit einem Maximum zwischen 450 und $480 \mathrm{~m} \mu$ wird auf den Multiplier geleitet. Das Fluorimeter mit dem Prinzip des Strahlenganges ist im Blockdiagramm angedeutet. Es wird zusammen mit einem Photometerbauteil „Eppendorf" ( $\mathrm{F}$ a. Netheler und Hinz, Hamburg; stabilisierte Stromversorgung für $\mathrm{Hg}$-Lampe und Mùltiplier, Verstärker usw.) und einem Registriergerät (Fa. Philips) betrieben.

\section{Sauerstoffmessung}

Der im Perfusionsmedium gelöste Sauerstoff wird amperometrisch mit der stabilisierten, spaltlosen Ganzglas-Platin-Elektrode nach LüBbERS $(25,26)$ (Elektroden und Verstärker: Fa. Eschweiler, Kiel) gemessen. Wegen des fehlenden Hämoglobin-Puffers ist die Differenz der Sauerstoffdrucke vor und hinter der Leber bei konstanter Durchströmungsgeschwindigkeit proportional der Atmungsgröße, die folgendermaßen berechnet wird:

$$
\begin{aligned}
\text { Atmung }= & \frac{\mathrm{AVD} \cdot \alpha \cdot 2 \cdot \mathrm{D}}{760 \cdot 22,4 \cdot \mathrm{FG}}[\mu \text { Atom } \mathrm{O} / \mathrm{Std} . / \mathrm{g} \text { (Frischgewicht) }] \\
\mathrm{AVD}= & \mathrm{pO}_{2 \text { arteriell }-\mathrm{pO}_{2} \text { venös. }(\text { torr) }} \\
\alpha= & \text { Bunsen'scher Absorptionskoeffizient }=0,023 \mathrm{~m} l \mathrm{O}_{2} / \mathrm{m} l \\
& 0,9 \text {-proz. } \mathrm{NaCl}, \text { bei } 760 \text { torr, } \mathrm{t}=36^{\circ} \\
\mathrm{D}= & \text { Durchströmungsgeschwindigkeit, (ml } / 60 \mathrm{Min} .) \\
\mathrm{FG}= & \text { sog. Frischgewicht derLeber }(\mathrm{g})=\text { Trockengewicht } \times 5 .
\end{aligned}
$$

\section{Metabolitanalysen}

Lactat und $\beta$-Hydroxybutyrat, bzw. Pyruvat und Acetoacetat werden im kombinierten optischen Test mit Hilfe der Lactatdehydrogenase und $\beta$-Hydroxybutyratdehydrogenase, Ammoniak mit Glutamatdehydrogenase (27) bestimmt. Kolorimetrische Bestimmung von Glukose (Glukoseoxydase-Methode) und Harnstoff. Sämtliche Testreagenzien und Enzyme: Fa. Boehringer, Mannheim. L-Alanin und Ölsäure: Fa. Roth. Karlsruhe. 
Barbiturate

Die untersuchten Barbiturate sind handelsübliche Präparate. Amytal (Fa. Merck, Darmstadt), mit $\mathrm{NaOH}$ auf $\mathrm{pH} 9$ neutralisiert. Nembutal $=$ Pentobarbital-Natrium (Fa. Abbot, Ingelheim), Pentothal = Thiopental-Natrium (Fa. Abbot, Ingelheim),

Evipan = Evipan-Natrium (Fa. Bayer, Leverkusen),

Luminal = Luminal-Natrium ( $\mathrm{Fa}$. Bayer, Leverkusen),

Veronal $=$ Barbital-Natrium (Fa. Merck, Darmstadt).

Tiermaterial

Wir verwenden weibliche Wistar II-Ratten von $200-250 \mathrm{~g}$, aus der Tierzüchterei Brünger (4801 Bokel), die mit einer vorwiegend kohlenhydrathaltigen Standarddiät („Altromin“) gefüttert werden. Unter Standardbedingungen erhalten die Tiere bis kurz vor Versuchsbeginn Futter und Wasser ad libitum. Für die Experimente unter Glukoneogenesebedingungen wird 24 Stunden vorher das Futter entfernt. Die Lebern dieser Tiere enthalten bei Versuchsbeginn weniger als $1 \%$ ihres Glykogens im gefütterten Zustand.

\section{Ergebnisse und Diskussion}

Amytal-Cyclus

In einer Serie von Perfusionsexperimenten unter Standardbedingungen wurden Atmungsgröße und Fluoreszenzintensität bei verschiedenen Amytalkonzentrationen gemessen. Ein repräsentatives Experiment dieser Serie, aus dessen Originalregistrierung Ausschnitte in Abbildung 2 gezeigt werden, soll im folgenden beschrieben werden. Die Kurven in Abbildung 2 geben die Registrierung der Oberflächenfluoreszenz und der Sauerstoffdrucke vor und hinter der Leber wieder. Sie sind von rechts nach links zu lesen. Bei konstanter Durchströmungsgeschwindigkeit ist der Abstand zwischen den beiden Sauerstoffkurven proportional zur Atmungsgröße der Leber. Am Anfang dieser Registrierung, nachdem 100 Minuten Perfusion in Normoxie vorausgegangen sind, beträgt die stationäre Atmung $290 \mu$ Atom 0/Std./g Leber.

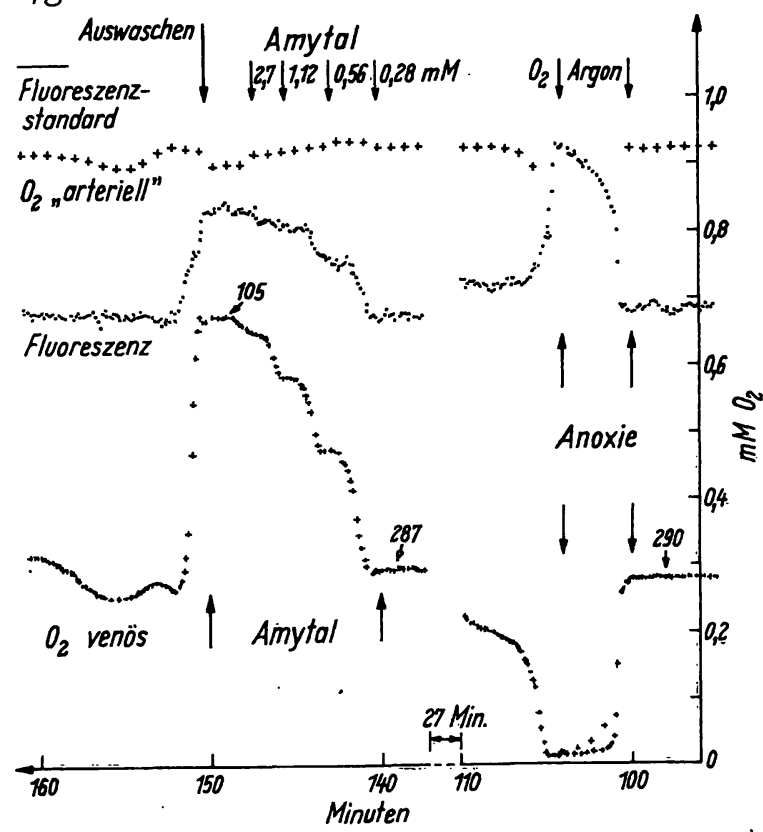

Abb. 2

Ausschnitte aus der Originalregistrierung des Experiments Nr.93/1

Zeitschreibung von rechts nach links.
94-110 Minuten: Anoxie-Cyclus; 137-161 Minuten: Amytal-Cyclus. ++++ Sauerstoffdrucke vor und hinter der Leber, amperometrisch gemessen mit Platinelektroden $(25,26)$.

Registrierung der Oberflächenfluoreszenz (primär $366 \mathrm{~m} \mathrm{\mu}$,

sekundär 450 480 $\mathrm{m} \mu$ ) (24). Anstieg der Fluoreszenzintensität und der
Sauerstoffdrucke bei Aufwärtsbewegung der Kurven.

sekundär $450-480 \mathrm{~m} \mu)(24)$. Anstieg der Fluoreszenzintensität und der
Sauerstoffdrucke bei Aufwärtsbewegung der Kurven.

Atmungsgrößen an der venösen Sauerstoffkurve: $\mu$ Atom 0/Std./g Lẹber (Frischgewicht).
Zur Charakterisierung der Präparation sei zunächst ein Anoxie-Cyclus (22) beschrieben. Nach Umschalten der Perfusion auf eine sauerstofffreie Lösung gleicher $\mathrm{Zu}$ sammensetzung (rechter Abschnitt der Registrierung: Anoxie) fallen beide Sauerstoffkurven auf Null. Die Fluoreszenzintensität steigt nach kurzer Latenz rasch an und geht nach etwa einer Minute in einen allmählichen Anstieg über. Der Anstieg nach 4 Minuten Anoxie dient als Bezugswert für die Fluoreszenzänderungen nach Zugabe von Barbituraten. Nach erneuter Zufuhr von Sauerstoff sinkt die Fluoreszenzintensität in einer Zweiphasenkinetik ab. Ungefähr $70 \%$ des Anstieges sind innerhalb einer Minute reversibel, während der Ausgangswert erst 10 Min. später erreicht wird, zu einem Zeitpunkt, an dem die Leber sich von einer Sauerstoffschuld erholt hat. Diese Sauerstoffschuld, die in der ersten Minute der Erholungsphase eine Atmungssteigerung von mehr als $50 \%$ bewirkt, beträgt in diesem Experiment $8 \mu$ Atom 0 und liegt in der Größenordnung des in 4 Minuten Anoxie entstandenen Lactats.

Nach einer Erholungsperiode von 30 Min. wird Amytal in steigenden Konzentrationen $(0,28-2,7 \mathrm{mM})$ zur Perfusionslösung hinzugegeben (linker Abschnitt der Abb. 2). Während bisher die Perfusion im rezirkulierenden System erfolgte, ist der Kreislauf jetzt unterbrochen, um eine Akkumulation des Amytals zu vermeiden. Entsprechend der ansteigenden Amytalkonzentration wird die Atmungsgröße schrittweise von 287 auf $105 \mu$ Atom 0 /Std./g vermindert. Die Restatmung bei 2,7 $\mathrm{mM}$ Amytal beträgt 37\% der Ausgangsatmung. In gleicher Weise steigt die Fluoreszenz schrittweise an und erreicht ein Maximum, das 75\% des Fluoreszenzanstieges nach 4 Minuten Anoxie entspricht. Nach 10 Min. dauernder Einwirkung auf die Leber wird Amytal durch eine frische Perfusionslösung ausgewaschen. Beide Effekte, sowohl Fluoreszenzanstieg als auch Atmungsdepression, haben sich innerhalb von 3 Min. zurückgebildet. Auch unter Berücksichtigung der vorübergehend geringeren Aufsättigung der Perfusionslösung (Abb. 2, obere Sauerstoffkurve) resultiert für einige Minuten ein leicht erhöhter Sauerstoffverbrauch.

\section{Reversibilität und Reproduzierbarkeit}

Dieser Cyclus von Amytal-Inhibition und Auswaschung läßt sich nach jeweils 20 Min. Erholung mehrmals mit guter Reproduzierbarkeit wiederholen. Entsprechende Daten für den Sauerstoffverbrauch findet man in Tabelle 1 . In den Zeilen $1 a$ und $1 b$, sowie $2 a$ und $2 b$ dieser Tabelle sind jeweils zwei aufeinanderfolgende AmytalCyclen an derselben Leber aufgezeichnet worden. Die Atmungsdepression bei entsprechenden Amytal-Konzentrationen, die rasche und vollständige Reversibilität durch Auswaschen und der vorübergehend leicht erhöhte Sauerstoffverbrauch in der Restitutionsphase sind innerhalb der Fehlergrenzen die gleichen. Hinsichtlich der Reversibilität der Atmungshemmung entsprechen die Oxybarbiturate Nembutal und Evipan (Zeile 3 bzw. 4) weitgehend dem Amytal. Anders verhält es sich mit dem Thiobarbiturat Pentothal (Zeile 5), wovon noch die Rede sein wird. 
Tab. 1

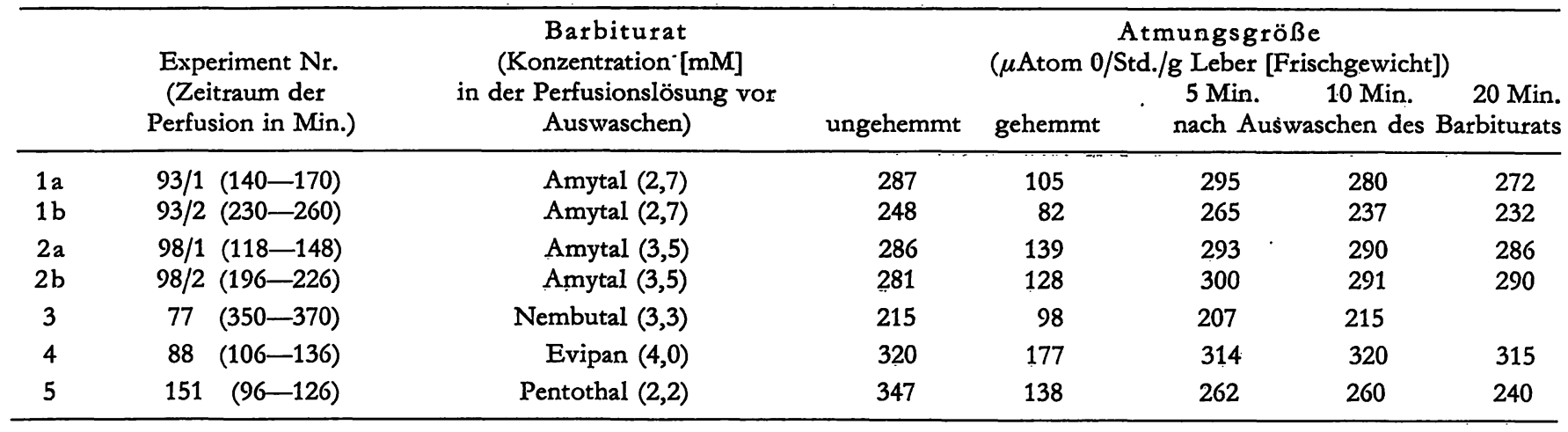

Titration der Atmungshemmung

Der Verlauf der Atmungshemmung in 17 Titrationen, entsprechend dem oben dargestellten Versuch (Abb. 2), sowie die Extrapolation auf den Grenzwert der Atmungshemmung, ist in Abbildung 3 dargestellt worden. Die Atmungshemmung wurde auf die Größe der Ausgangsatmung $(=100 \%$ ) bezogen. Um eine Extrapolation auf den Grenzwert zu ermöglichen, sind Konzentrationen des Hemmstoffes und Abnahme der Atmungsgröße reziprok aufgetragen worden. Die Meßwerte jedes einzelnen Experimentes sind durch ein besonderes Symbol gekennzeichnet. Ausgefüllte Kreise entsprechen dem in Abbildung 2 dargestellten Experiment.

Die Meßwerte lassen sich einer Kurve von annähernd hyperbolischer Funktion zuordnen, deren Übertragung in die nichtreziproke Darstellung man in Abbildung 4

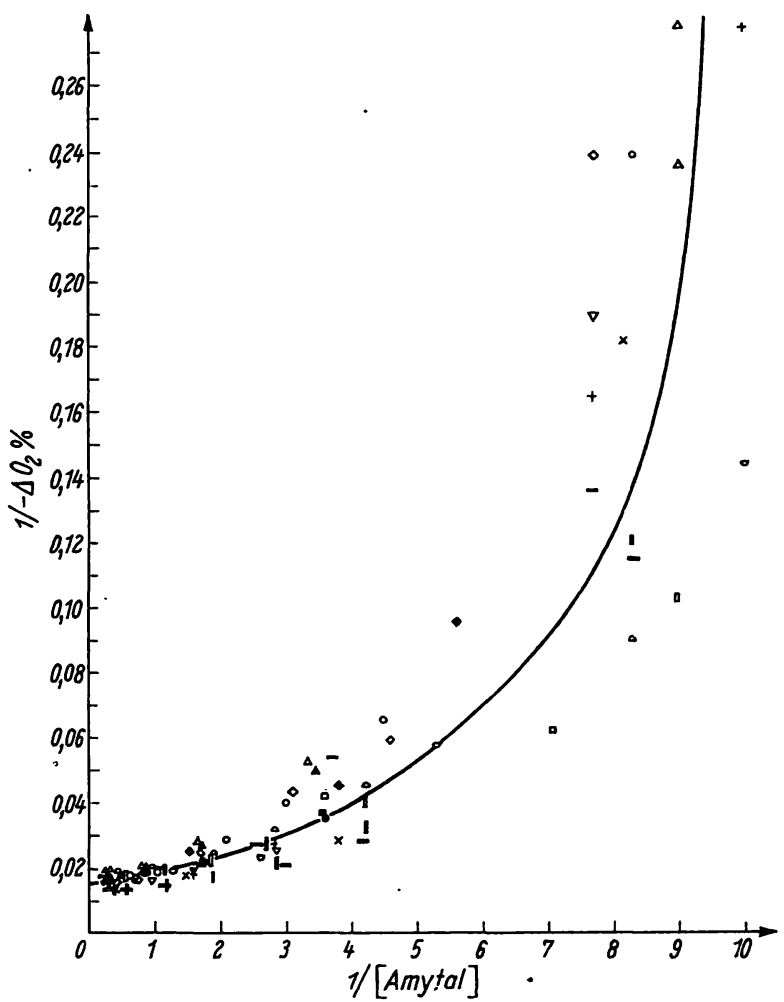

Abb. 3

Beziehung zwischen Atmungshemmung und Amytalkonzentration $(\mathrm{mM})$ in reziproker Auftragung.

Atmungshemmung $\left(-\Delta \mathrm{O}_{2} \%\right)$ : Differenz zwischen ungehemmter und gehemmter Atmung, Ausgangsatmung $=100 \% .17$ Experimente. Die Meßwerte jedes einzelnen Experimentes sind durch ein besonderes Symbol gekennzeichnet.

$\bullet=$ Experiment Nr. 93/1 (Abb. 2) bzw. 9 findet. Wie man sieht, ist der Verlauf biphasisch. Sehr geringe Konzentrationen von Amytal bewirken noch keine Atmungshemmung, dagegen aber bereits eine Fluoreszenzsteigerung, wie unten gezeigt werden soll. Die Extrapolation auf den Grenzwert bei maximaler Amytalkonzenträtion ergibt nach dieser Darstellung eine Atmungshemmung von $66 \%$ der Ausgangsatmung. Unter Berücksichtigung dieses Maximalwertes läßt sich aus den Darstellungen der Abbildungen 4 und 9 für den halbmaximalen Effekt eine Konzentration von 0,34 $\mathrm{mM}$ ablesen (s. a. Tab. 3). Dieser Wert kann als ein $\mathrm{Maß}$ für die Amytalsensibilität der perfundierten Leber unter Standardbedingungen angesehen werden.

Wegen der Komplexität des energieliefernden Stoffwechsels, in den Amytal an umschriebenerStelle eingreift, ist die Sensibilität des Systems gegenüber dem Hemm-

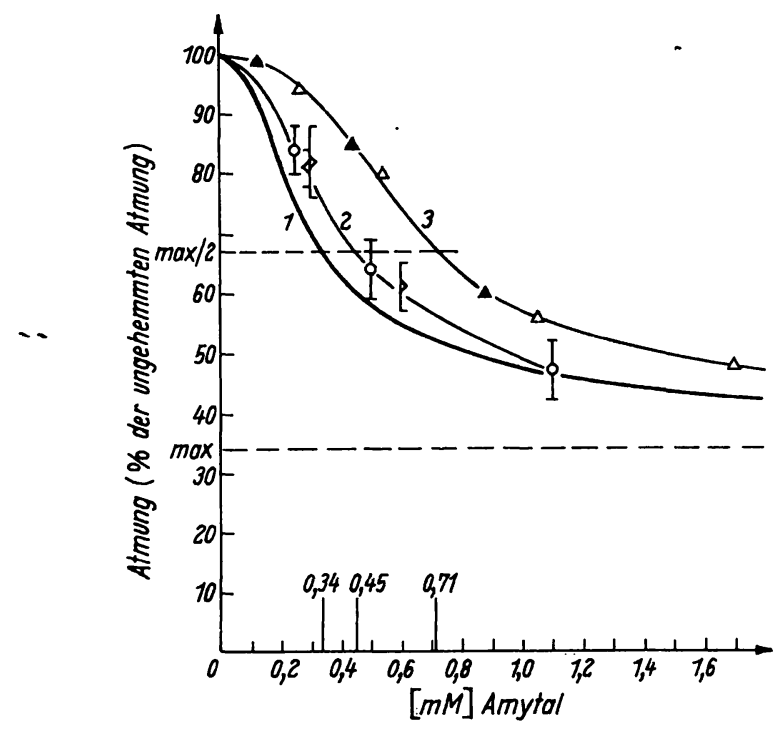

Abb. 4

Titrationskurven für die Hemmung der Leberatmung durch Amytal unter verschiedenen Perfusionsbedingungen.

Kurve 1: - Leber von gefütterten Ratten (glykogenreich), Perfusion im offenen System, Obertragung der Linie aus Abb. 3 in die nichtreziproke Darstellung.

Kurve 2: $\mathrm{O}-\mathrm{O}$ Leber von gefütterten Ratten, jedoch Perfusion im Kurve 2: $0-0$ Leber von gefütterten Ratten, jedoch Perfusion im (Nr. 162, 3, 4, 6, 8) Mittelwerte mit Standardabweichungen.

Kurve 3: $\triangle$ Experiment Nr. 229, $\triangle$ Experiment Nr. 248. Leber von "Hungerratten" (24 Stunden Nahrungskarenz, glykogenfrei), Perfusion im geschlossenen System mit Medium $B$ plus Olsẩure $(0,6 \mathrm{mM})$ $\triangle$ Lebern von "Hungerratten", Medium B. 11 Experimente mit Lebern von" $0,3 \mathrm{bzw}, 0,6 \mathrm{mM}$ Amytal.

$\triangle$ Lebern von "Hungerratten", Medium B, jedoch ohne Albumin 4 Experimente mit 0,3 mM Amytal. Mittelwerte mit Standardabweichungen.

Maximale Atmungshemmung nach Extrapolation auf den Grenzwert $66 \%$ der Ausgangsatmung ( $\pm 8 \%)$, keine signifikanten Unterschied $z w i s c h e n$ den einzelnen Serien. Die Konzentration für halbmaximale Atmungshemmung ist angegeben. 
stoff abhängig von der vorliegenden Stoffwechselsituation. Man kann deshalb nicht von der Amytalsensibilität der Leber schlechthin, sondern nur von der Sensibilität der Leber unter bestimmten Perfusionsbedingungen sprechen. Die unterschiedliche Sensibilität bei verschiedenen Versuchsbedingungen ist aus Abbildung $4 \mathrm{zu}$ ersehen. Neben den bislang beschriebenen Experimenten an Lebern von normal gefütterten Ratten, durchströmt im offenen Perfusionssystem (Kurve 1), zeigt diese Abbildung die Titrationskurve bei geschlossenem Perfusionssystem (Kurve 2). Hier akkumulieren die unter der Einwirkung des Amytals von der Leber ausgeschiedenen Metabolite, insbesondere Lactat (vgl. unten). Die maximale Hemmbarkeit der Atmung ist unverändert, ihre Sensibilität gegenüber Amytal jedoch herabgesetzt. Die Konzentration für halbmaximalen Effekt steigt von 0,34 auf $0,45 \mathrm{mM}$. Wesentlich geringer ist die Amytalsensibilität in den Experimenten der Kurve 3. Hier wurden nach 24stündiger Nahrungskarenz entnommene Lebern mit Medium B (s. methodischer Teil) plus Ölsäure $(0,6 \mathrm{mM})$ durchströmt. Auch hier wird bei der Titration eine maximale Atmungshemmung von annähernd $66 \%$ erreicht. Die Konzentration für halbmaximalen Effekt liegt allerdings bei $0,7 \mathrm{mM}$. Weder der Status des Hungerns, noch die veränderte Perfusionslösung (Anwesenheit von Albumin), haben einen merklichen Einfluß auf die Amytalsensibilität. Das geht ebenfalls aus Abbildung 4 hervor. Die dort zusätzlich eingetragenen Werte der Atmungshemmung stammen von Lebern im Status der Glukoneogenese. Sie unterscheiden sich nur unwesentlich von der Kurve 2. Die verringerte Amytalsensibilität bei Gegenwart von Fettsäuren ist demnach auf den anderen Typ des mitochondrialen Katabolismus zurückzuführen. Unten werden wir zeigen, daß unter Amytal auch die Ketogenese und damit der nicht-pyridinnucleotid-abhängige Anteil an der Gesamtatmung steigt.

Chance und Hess (19) haben in den Versuchen mit Ascitestumorzellen eine geringere Amytalsensibilität der Atmung $(0,8 \mathrm{mM})$ beobachtet, als wir sie für ein intaktes Organ beschreiben. In einer vorausgegangenen Arbeit (22) haben wir bei dem Vergleich der Konzentrationen für halbmaximalen Effekt an Ascitestumor- zellen $(0,8 \mathrm{mM})$ und an der perfundierten Leber unter Standardbedingungen (0,3 mM) die Möglichkeit einer zellspezifischen Sensibilität der Mitochondrientypen gegenüber Barbituraten diskutiert. Diese Möglichkeit ist zwar nicht auszuschließen, jedoch sind im Hinblick auf unsere neueren Ergebnisse Stoffwechselunterschiede als Ursache der verschiedenen Sensibilitäten wahrscheinlicher. In den Versuchen von ChaNCE und Hess wurde dem Inkubationsmedium kein Substrat zugesetzt. Da Ehrlich-Ascitestumorzellen als endogenes Substrat vorwiegend Fette enthalten (28) und außerdem über einen intensiven Fettsäurekatabolismus verfügen (29), wird möglicherweise dieser Stoffwechseltyp ihre geringe Amytalsensibilität bedingen.

\section{Titration in vivo und in vitro}

In der Tabelle 2 sind die Amytalkonzentrationen für halbmaximale Atmungshemmung bei isolierten Lebermitochondrien denen bei der perfundierten Leber gegenübergestellt worden. Die Amytalsensibilität der Leber mit vorwiegendem Kohlenhydratkatabolismus (endogenes Substrat: Glykogen) liegt im gleichen Bereich wie die von Mitochondrienpräparationen ohne Malonat- oder Succinatzusatz. Angaben über die Barbituratsensibilität von Lebermitochondrien mit intensivem Fettsäurekatabolismus konnten wir nicht finden. Möglicherweise bestand bei der Präparation, deren geringe Amytalsensibilität ERNSTER beschreibt (9), eine vorwiegende Verbrennung von endogenem Substrat, so da $B$ diese Mitochondrienpräparation der perfundierten Leber mit Ölsäureumsatz vergleichbar ist. Nach den Untersuchungen von CHANCE und Hollunger (16) hängt die Amytalsensibilität phosphorylierender Mitochondrien ("state 3" nach Chance $(30,31)$ ) sowohl vom Wasserstoffdonator als auch von der Gegenwart von Malonat ab. Für die Veratmung von $\beta$-Hydroxybutyrat beträgt die halbmaximal wirkende Konzentration $0,35 \mathrm{mM}$, die sich bei Gegenwart von Malonat auf $0,19 \mathrm{mM}$ verringert. Die mit $0,12 \mathrm{mM}$ höchste Sensibilität wird bei Malat-Glutamat als Substrat in Gegenwart von Malonat gefunden. In Abwesenheit von Malonat bewirken kleine Amytalkonzentrationen auch bei Lebermitochondrien keine sofortige Atmungshemmung. Die Titrations-

Tab. 2

Amytal-Konzentration [mM] für halbmaximalen Effekt

Autoren Objekt $\quad$ Substrat $\quad$ Pyridinnucleotid

Atmungshemmung (Fluoreszenz)

ERNSTER (9) (1955) Leber-Mitochondrien (Ratte)

Aldridge u. Parker (14) (1960) Leber-Mitochondrien (Ratte)

Chance u. Hollunger (16) Leber-Mitochondrien (Ratte)

(1963)

SCHOLZ, SCHWARZ u. BüCHER (1966) hämoglobinfrei perfundierte Leber (Ratte)

Chance u. Hess (19) (1959)

Ascites-Tumorzellen

0,6

0,21

0,35

0,19

0,12

7,0

$\beta$-Hydroxybutyrat mit Malona
Malat-Glutamat mit Malonat Succinat-Glutamat endogen (Glykogen) endogen (Glykogen, Lactat-Accumulation) Olsäure endogen 
kurven zeigen einen sigmoiden Verlauf, wie er für unsere Versuche charakteristisch ist (Abb. 4 bzw. 9). Nach Zusatz von Malonat zur Mitochondriensuspension fehlt diese Verzögerungsphase. Die Titrationskurve ist jetzt nicht-sigmoid. Die Autoren führen den Einfluß des Malonats auf die Unterdrückung der Succinatatmung zurück. Es ist jedoch zu bedenken, daß der Effekt auch mit $\beta$-Hydroxybutyrat als Substrat beobachtet wurde. Aus ihren Angaben ist der Anteil des endogenen Substrates an der mitochondrialen Atmung nicht ersichtlich. Nach KLINGENBERG enthalten die Lebermitochondrien erhebliche Mengen an endogenem Substrat (32), vorwiegend Fettsäuren (33), dessen Veratmung mit Malonat unterdrückt werden kann (34).

Im Gegensatz zur Amytalsensibilität ist der durch Amytal hemmbare Anteil der Gewebsatmung unabhängig vom Status der Leber und vom umgesetzten Substrat. Unter sämtlichen Versuchsbedingungen, die in der Legende zu Abbildung 4 angegeben sind, finden wir nach Extrapolation auf den Grenzwert eine maximale Atmungshemmung von $66 \%$ der Ausgangsatmung (mit einem Variationsbereich von $\pm 8 \%$ ). Der Rest von $34 \%$ besteht etwa zur Hälfte aus cyanidresistentem Sauerstoffverbrauch (22). Demnach kann für Lebermitochondrien in situ eine amytalresistente Atmung von etwa $15 \%$ der Atmung im stationären Zustand angenommen werden, was einer Atmungsgröße von 30-40 $\mu$ Atom 0/Std./g Leber entspricht. Ein größerer Beitrag der Succinatatmung ist unwahrscheinlich, da Amytal den CitratCyclus blockiert. Dieser Anteil ist also in erster Linie der Veratmung von $\alpha$-Glycerophosphat und Cholin zuzuschreiben. Tatsächlich bewegen sich die in euthyreotischen Lebern gemessenen Aktivitätsgehalte der mitochondrialen Glycerophosphatoxydase in der GröBenordnung eines Durchsatzes von $15 \mu \mathrm{Mol} / \mathrm{Std}$./g Leber (35).

\section{Korrelation von Atmung und Fluoreszenz}

Kurzzeitige Änderungen der Oberflächenfluoreszenz (primär $366 \mathrm{~m} \mu$, sekundär $450-480 \mathrm{~m} \mu$ ) spiegeln entsprechende Bewegungen im Redoxstatus der zellulären Pyridinnucleotide wieder. CHANCE und sein Arbeitskreis, deren Technik der Fluoreszenzmessung wir anwenden (24), haben diese Zusammenhänge in zahlreichen Untersuchungen gezeigt (36-39). Auch im Leberparenchym, in dessen Mitochondrien zwar das TPN-System einen relativ hohen Anteil am Pyridinnucleotid-Bestand hat, ist der Beitrag des DPN-Systems an den Fluoreszenzänderungen maßgebend $(22,40)$. Ein weiterer Beweis für diesen Sachverhalt ist durch die in Abbildung 5 dargestellte Korrelation zwischen Atmungshemmung und Fluoreszenzsteigerung nach Einwirkung von Amytal auf die Leber gegeben. In dieser Abbildung sind die Meßwerte aus jeweils 10 korrespondierenden Titrationen der Atmungshemmung und der Fluoreszenzsteigerung enthalten. Die aus einer größeren Serie ermittelten mittleren Grenzwerte für maximale Atmungshemmung (=66\% der Ausgangsatmung, s. Abb. 3) und für maximalen Fluoreszenzzuwachs $(=80 \%$ des Anstiegs

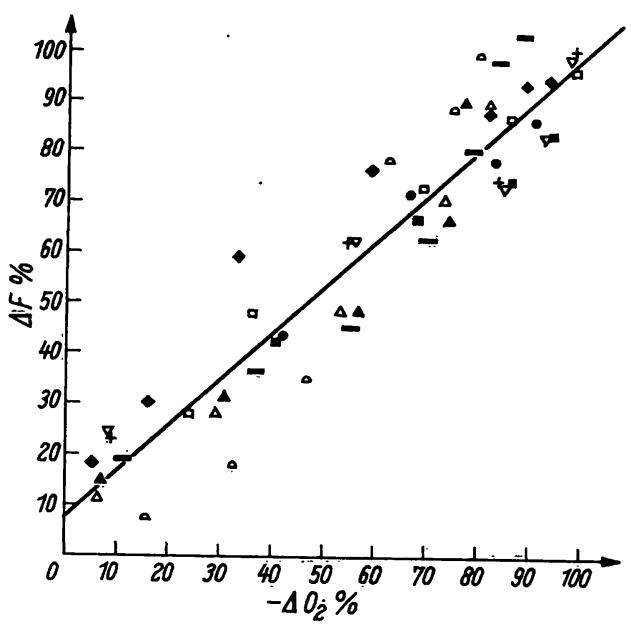

Abb. 5

Korrelation zwischen Atmungshemmung $\left(-\Delta \mathrm{O}_{2} \%\right)$ und Fluoreszenzanstieg $(\triangle \mathrm{F} \%)$.

Einzelwerte aus 10 Experimenten ( $\bullet$ Experiment Nr. 93/1 aus Abb. 2). Mittlere Grenzwerte für maximale Atmungshemmung und maximalen

Fluoreszenzanstieg $=100$.
Regressionsgerade: $\Delta \mathrm{F} \%=7,6+0,91 \cdot\left(-\Delta \mathrm{O}_{2} \%\right)$

nach 4 Min. Anoxie) wurden gleich 100 gesetzt. Die Einzelmeßwerte wurden auf diese Maximalwerte bezogen. Die Regressionsgerade, ermittelt aus 53 Wertepaaren, $\Delta \mathrm{F} \%=7,6+0,91 \cdot\left(-\Delta 0_{2} \%\right)$, schneidet die Ordinate bei $7-8 \%$ des Maximalwertes. Dieser Ordinatenabschnitt repräsentiert einen Fluoreszenzzuwachs ohne gleichzeitige Atmungshemmung, der bei geringen Amytalkonzentrationen auftritt. In diesem Zustand der Hemmung ist die DPNH-Oxydation bereits eingeschränkt, die Oxydation nicht-pyridinnucleotid-spezifischer Substrate ist dagegen kompensatorisch gesteigert. Wir sehen in diesem Befund zusätzlich einen Hinweis auf den ADP-kontrollierten Status der Mitochondrien („state 4" nach CHANCE) in der stationären, perfundierten Leber, den wir in einer vorausgegangenen Arbeit (22) erörtert haben.

$\mathrm{Da}$ eine wesentliche Änderung des ,fluorescence enbanceñènt" (40) unter der Einwirkung von Amytal nicht zu erwarten ist, dürfen wir in erster Annäherung schließen, $\mathrm{da} ß$ der Zuwachs der Fluoreszenz proportional dem $\mathrm{Zu}$ wachs des mitochondrialen DPNH ist. Für eine halbmaximale Steigerung der Fluoreszenz ist eine Amytalkonzentration in der Perfusionslösung von 0,33 $\mathrm{mM}$ erforderlich. Dieser Wert steht in Übereinstimmung mit den Untersuchungen von CHANCE und Hollunger (16), die bei der Titration der Pyridinnucleotid-Reduktion in isolierten Mitochondrien halbmaximale Effekte bei Konzentrationen $z$ wischen 0,22 ( $\beta$-Hydroxybutyrat mit Malonat) und 0,32 $\mathrm{mM}$ (Malat-Glutamat mit Malonat) finden (s. a. Tab. 2).

Die enge Korrelation zwischen Atmungshemmung und Fluoreszenzanstieg, wie sie mit diesen Messungen erstmals für ein Gewebe demonstriert wird, erscheint uns wesentlich für die Deutung von Fluoreszenzkurven, die zum Beispiel beim Anoxie-Cyclus beobachtet werden $(20,22)$. Dieser Befund macht wahrscheinlich, daß mitochondriale Ereignisse zu kurzfristigen Bewegungen der Oberflächenfluoreszenz den größten Beitrag liefern. Verantwortlich dafür ist fraglos die bedeutende Ver- 


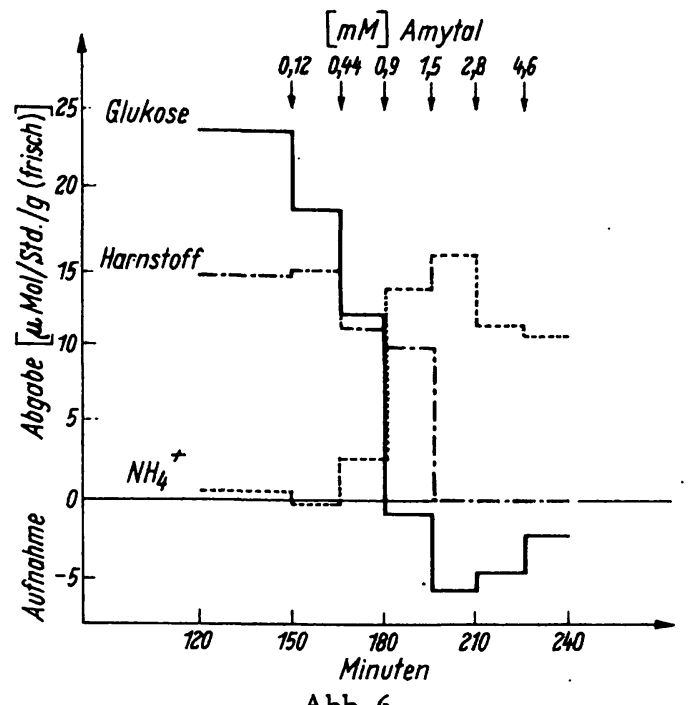

Abb. 6

Glukoneogenese und Harnstoffsynthese: Abgabe bzw. Aufnahme von Glukose, Harnstoff und Ammoniak ( $\mu \mathrm{Mol} / \mathrm{Std} . / \mathrm{g}$ (Frischgewicht)) im Perfusionsexperiment Nr. 248, vor und nach Zugabe verschiedener Amytalkonzentrationen.

Leber einer "Hungerratte", perfundiert mit Medium B plus Olsäure $(0,6 \mathrm{mM})$. Berechnung der Produktionsraten aus der Differenz der Konzentrationen in der Perfusionslösung, entnommen im Abstand von 15 Min. (Gesamtvolumen $170 \mathrm{ml}$, Durchströmungsgeschwindigkeit $40 \mathrm{~m} /$ Min.). Sauerstoffverbrauch siehe Abbildung 4 Kurve 3.

stärkung der Fluoreszenz des DPN-Systems in nichtentkoppelten Mitochondrien (40).

\section{Einfluß auf biosynthetische Funktionen}

Abbildung 6 demonstriert den Einfluß von Amytal auf zwei wichtige biosynthetische Funktionen der Leber: Glukoneogenese und Harnstoffsynthese. Die Leber wurde einem Tier nach 24-stdg. Nahrungskarenz entnommen und mit Medium B unter Zusatz von $10 \mathrm{mM}$ Alanin und 0,6 mM Ölsäure durchströmt. Unter diesen Bedingungen wird aus Alanin Glukose synthetisiert. Die Energie wird durch die Verbrennung der Fettsäure unter geringer Ketogenese geliefert (Abb. 7). Man erkennt aus Abbildung 6, daß die beiden biosynthetischen Funktionen sich in ihrer Amytalsensibilität unterscheiden.

Während die Glụkoneogenese bereits bei geringen Amytalkonzentrationen gehemmt und bei halbmaximaler Atmungshemmung $(0,7 \mathrm{mM}$ Amytal) vollständig unterdrückt wird, ist die Harnstoffsynthese zunächst kaum beeinflußt. Offensichtlich sind für die Glukoneogenese Wasserstoffverschiebungen notwendig, die durch Amytal verändert werden. Sehr wahrscheinlich liegt der Angriffspunkt auf die Glukoneogenese bei der Oxydation von Alanin zu Pyruvat (Gl. (4)) durch Vermittlung der Transaminierung von $\alpha$-Ketoglutarat (Gl. (1)) und der Oxydation von Glutamat (Gl. (2)), entsprechend folgender Redaktionsgleichungen:

(1) Alanin $+\alpha$-Ketoglutarat $\longrightarrow$ Pyruvat + Glutamat

(2) Glutamat $+\mathrm{DPN}+\overline{\mathrm{H}}_{2} \mathrm{O} \longrightarrow \alpha$-Ketoglutarat +

(3) $\mathrm{DPNH}_{2}+\mathrm{FAD}$ $\mathrm{DPNH}_{2}+\mathrm{NH}_{3}$ $-\rightarrow \mathrm{DPN}+\mathrm{FADH}_{2}$ Amytal

(4) Alanin + $\mathrm{FAD}+\mathrm{H}_{2} \mathrm{O} \longrightarrow$ Pyruvat $+\mathrm{FADH}_{2}$ $+\mathrm{NH}_{3}$
Die hohe Sensibilität der Glutamatoxydation gegenüber Amytal ist bereits zu einem sehr frühen Zeitpunkt an Gewebshomogenaten von Meerschweinchenhirn (1) nachgewiesen und später an isolierten Lebermitochondrien bestätigt worden (16).

Dagegen fordert die Harnstoffsynthese vom mitochondrialen Stoffwechsel nur energiereiches Phosphat, das bei geringer Atmungshemmung noch zur Verfügung gestellt wird. Die Harnstoffsynthese ist erst wesentlich vermindert, wenn die Atmungshemmung etwa 40\% der Gesamtatmung übersteigt. Bereits bei nur mäßig eingeschränkter Harnstoffsynthese werden Ammoniumionen freigesetzt. Dieser Prozeß erreicht sein Maximum bei einer Hemmung der Gesamtatmung um 50\% (1,5 mM Amytal), bei der die Harnstoffsynthese zum Erliegen kommt, und hält auch bei maximaler Atmungshemmung an.

\section{Ketogenese}

Bedeutungsvoll für die mitochondriale Energielieferung in Gegenwart von Amytal ist die stark ansteigende Bildung von $\beta$-Hydroxybutyrat. In dem oben besprochenen Experiment erreicht sie einen Wert von $30 \mu \mathrm{Mol} / \mathrm{Std} . / \mathrm{g}$ (Abb. 7). Durch diesen Prozeß kann die Hälfte des beim Fettsäureabbau anfallenden DPNspezifischen Wasserstoffs aufgefangen werden, so daß mit der Oxydation eines $\mathrm{DPNH}_{2}$ zwei flavinspezifische Wasserstoffpaare für die oxydative Phosphorylierung zur Verfügung stehen. Dieser Mechanismus ermöglicht eine partielle Umgehung des gehemmten Schrittes in der Atmungskette und erklärt die geringe Amytalsensibilität der Atmung einer Leber mit intensivem Fettsäurekatabolismus (Kurve 3 in Abb. 4). Bei Lebern von normal gefütterten Tieren mit fast ausschließlichem Kohlenhydratabbau finden wir nach Amytal ebenfalls eine Produktion von $\beta$-Hydroxybutyrat (un-

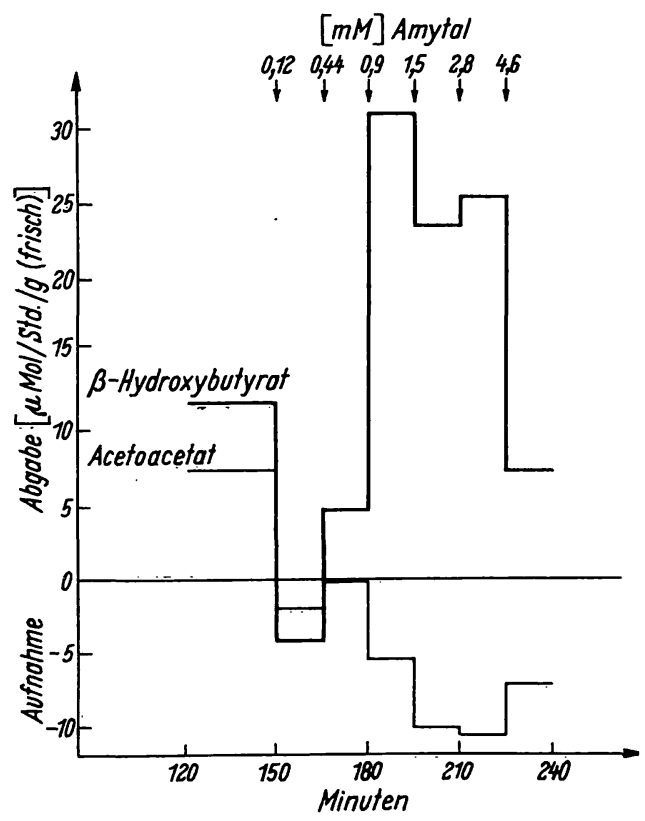

Abb. 7

Ketogenese: Abgabe bzw. Aufnahme von $\beta$-Hydroxybutyrat und Acetoacetat.

Experiment Nr. 248, siehe Legende zu Abb. 6 
gefähr $4 \mu \mathrm{Mol} / \mathrm{Std} . / \mathrm{g}$; s. Abb. 8), so daß auch hier eine Umschaltung im System des mitochondrialen Katabolismus zu exkennen ist. Bemerkenswerterweise geht 'dieser vermehrten Ketogenese zunächst eine Drosselung bei sehr niedrigen Amytalkonzentrationen voraus (Abb. 7). Die Ursache dieses Effektes bedarf weiterer Klärung.

Mitochondriale und extramitochondriale Redoxpotentiale

In einer Serie von Experimenten wurde bei der Amytaltitration das geschlossene Kreislaufsystem beibehalten, so daß Amytal und Metabolite akkumulierten. Die zu den einzelnen Zeitabschnitten von jeweils 10 Minuten auf die Leber einwirkenden Amytalkonzentrationen ließen sich berechnen. Die Titration der Atmungshemmung wurde bereits in Abbildung 4 (Kurve 2) beschrieben. Im geschlossenen Perfusionssystem stellt sich in kurzer Zeit ein Gleichgewicht zwischen dem intrazellulären Raum der Leber und der Perfusionslösung ein, so daß Metabolitanalysen in der Perfusionslösung Rückschlüsse auf die Verhältnisse im Gewebe zulassen. Im Falle von leicht permeablen Substanzen, die an Redoxvorgängen beteiligt sind, verfügen wir über Indikatorsysteme, die eine Abschätzung der zellulären Redoxpotentiale des DPN-Systems erlauben. Wenn das zwischen den jeweiligen Redoxpartnern vermittelnde Enzym im zellulären Raum exakt lokalisierbar ist, lassen sich mit dieser Methode auch Redoxvorgänge in den verschiedenen Kompartimenten der Zelle beobachten.

Ein wertvolles Indikatorsystem ist das Redoxpaar Lactat-Pyruvat, das wegen der ausschließlichen Lokalisation der Lactatdehydrogenase im extramitochondrialen Raum (42) eine sichere Aussage über das dort herrschende Redoxpotential des DPN-Systems zuläßt. Ein Indikator für das mitochondriale DPN-System liegt im Redoxpaar $\beta$-Hydroxybutyrat-Acetoacetat vor. Beide Substratpaare enden in einer sog. Sackgasse des intermediären Stoffwechsels und sind folglich als Redoxindikatoren besser geeignet als z. B. das in einer Stoffwechselkette liegende Paar $\alpha$-Glycerophosphat-Dihydroxyacetonphosphat.

Bei der hämoglobinfreien Leberperfusion liegt der Quotient Lactat/Pyruvat unter normoxischen Bedingungen bei Werten um 8 (Abb. 8). Die Werte bei der blutigen Ieberperfusion und im Rattenserum liegen im gleichen Bereich $(43,44)$. Nach 10 Min. Einwirken von Amytal $(0,25 \mathrm{mM})$ ist der Quotient auf 11, nach weiteren $10 \mathrm{Min}$. jedoch bei der doppelten Konzentration, auf 15 angestiegen. Bei maximaler Amytalkonzentration ( $3 \mathrm{mM}$ ) erreicht der Quotient Lactat/Pyruvat Werte von ungefähr . 30 und unterscheidet sich damit nicht von Messungen in der Anoxie. Das Redoxpotential dieses Systems und - entsprechend den vorausgegangenen Überlegungen auch des extramitochondrialen DPN-Systems fällt von -231 auf $-247 \mathrm{mV}$. Gleichzeitig steigt der Quotient $\beta$-Hydroxybutyrat-Acetoacetat von Werten um 1 auf Werte zwischen 3 und 6. Das Redoxpotential des mitochondrialen DPN-Systems, das mit der $\beta$-Hydroxybutter-
säure-Dehydrogenase in Verbindung steht, fällt von -268 auf $-289 \mathrm{mV}$ ab. Die „Istpotentiale“ (41) $\mathrm{E}^{\prime}=\mathrm{E}_{0}^{\prime}$ $-30,7 \cdot \lg \frac{\text { RED }}{\text { OX }}(\mathrm{mV})$ wurden berechnet unter Annahme eines Normalpotentials $\mathrm{E}_{0}^{\prime}$ (bei $\mathrm{pH} 7$ und $37^{\circ}$ ) von $-204 \mathrm{mV}$ für das Substratpaar Lactat-Pyruvat, bzw. von -270 für $\beta$-Hydroxybutyrat-Acetoacetat (35).

Glykolyse

In den hier beschriebenen Versuchen besteht für Lactat im Zeitraum von $20 \mathrm{Min}$. vor Amytalapplikation eine weitgehend ausgeglichene Bilanz (Abb. 8). Unmittelbar nach Einwirken des Barbiturats setzt eine starke Glykolyse ein, die zu einer massiven Ausschüttung von Lactat führt. Die Glykolyserate ist dosisabhängig. Ihre Titrationskurve zeigt jedoch keinen sigmoiden Verlauf, wie er für die Titration der Atmungshemmung charakteristisch ist (Abb. 4, Kurve 2). In einem Bereich, in dem die Atmung erst halbmaximal gehemmt ist, erreicht die Glykolyse mit einer Lactatproduktion von $100 \mu \mathrm{Mol} / \mathrm{Std}$./g Leber fast ihren Höchstwert.

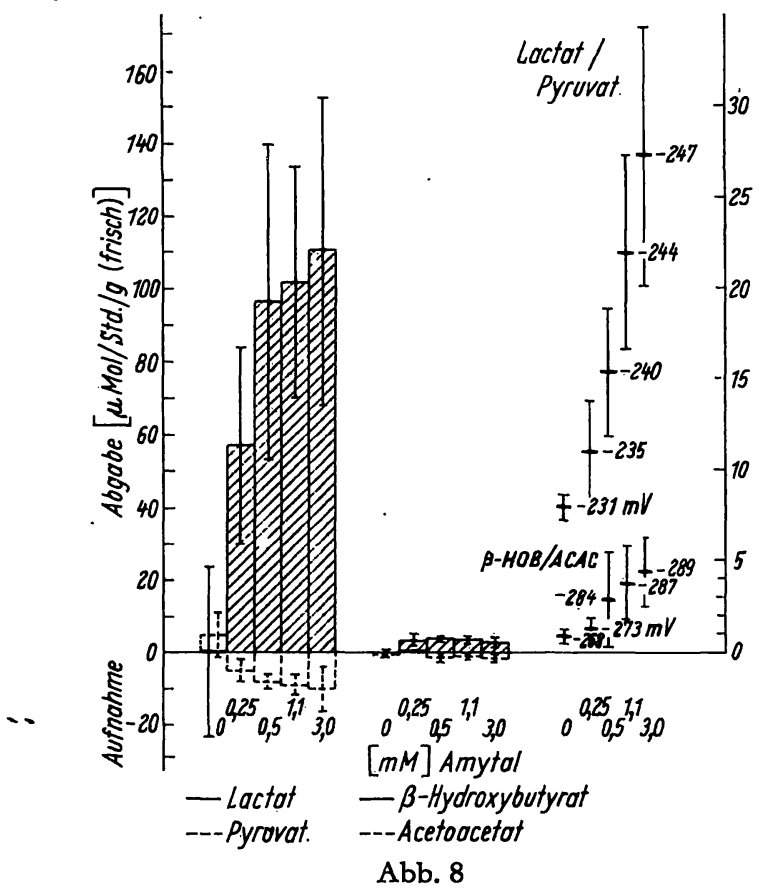

Abgabe bzw. Aufnahme von Lactat, Pyruvat, $\beta$-Hydroxybutyrat und Acetoacetat bei Lebern von normal gefütterten Ratten, perfundiert im geschlossenen System, vor und nach Zugabe von Amytal.

Quotienten der Konzentrationen dieser Substratpaare in der PerfusionsDie einzelnen Amytalkonzentrationen wirkten jeweils $10 \mathrm{Min}$. auf die Experiment Nr. 162, 3, 4, 6, 8. Mittelwerte und Standardabweichungen. Sauerstoffverbrauch siehe Abb. 4, Kurve 2

Vergleich der Wirkungen verschiedener Barbiturate auf Atmung und Fluoreszenz

In der gleichen Versuchsanordnung, wie wir sie für das Experiment aus Abbildung 2 beschrieben haben, wurden die Wirkungen weiterer Barbiturate auf die perfundierte Leber untersucht. Die Ergebnisse sind in Tabelle $3 \mathrm{zu}-$ sammengefaßt. Sie zeigt in Spalte 2 und 4 die Grenzwerte für maximale Atmungshemmung (bezogen auf die Aưsgangsatmung), bzw. für maximalen Fluoreszenzanstieg (bezogen auf den Fluoreszenzzuwachs nach 4 Min. 
Tab. 3

\begin{tabular}{|c|c|c|c|c|}
\hline & \multicolumn{2}{|c|}{ Rtmung } & \multicolumn{2}{|c|}{ Fluoreszenz } \\
\hline Barbiturate & $\begin{array}{c}\text { Max. Hemmung } \\
\text { (ungehemmt }=100 \text { ) }\end{array}$ & $\begin{array}{l}\text { Konzentration } \\
\text { für halbmax. Effekt } \\
(\mathrm{mM})\end{array}$ & $\begin{array}{l}\text { Maximaler Anstieg } \\
\text { (Anstieg nach } 4 \text { Min. } \\
\text { Anoxie }=100 \text { ) }\end{array}$ & $\begin{array}{l}\text { Konzentration } \\
\text { für halbmax. Effekt } \\
(\mathrm{mM})\end{array}$ \\
\hline
\end{tabular}

AMYTAL

5-Äthyl-5-(3-Methyl-Butyl)-Barbital

$(\mathrm{n}=17)$

NEMBUTAL

5-Äthyl-5-(1-Methyl-Butyl)-Barbital $(n=6)$

$66 \pm 8$

0,34

$80 \pm 10$

$62 \pm 4$

0,36

100

PENTOTHAL

5-Äthyl-5-(3-Methyl-Butyl)-Barbital $(n=3)$

EVIPAN

1-N-Methyl-5-Methyl-5-Cyclohexenyl-

Barbital ( $n=5)$

LUMINAL

5-Äthyl-5-Phenyl-Barbital $(n=1)$

VERONAL

5-Di-Äthyl-Barbital $(n=4)$
$68 \pm 3$
0,37

$50 \pm 4$

0,95

0,85

40

$25 \pm 5$
0,33

0,41

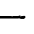

1,2

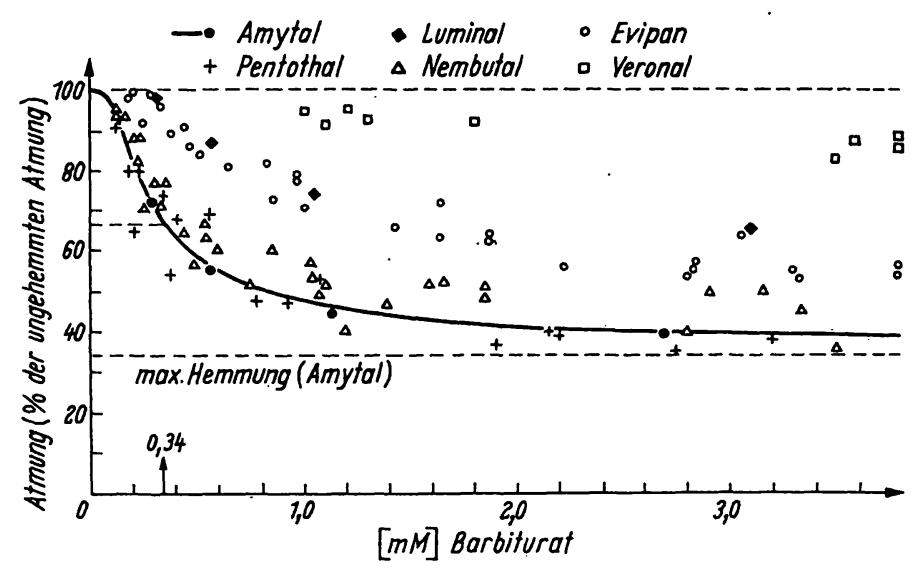

Abb. 9

Titrationskurven für die Atmungshemmung durch verschiedene Barbiturate bei perfundierten Rattenlebern.

Amytal: Ausgezogene Linie, ermittelt aus 17 Experimenten, entsprechend Abb. 3. - Experiment Nr. 93/1 aus Abb. 2

Nembutal: Einzelwerte aus 6 Experimenten. Pentothal (3 Expt.), Evipan (5 Expt.), Luminal (1 Expt.) und Veronal (4 Expt.).

Die maximale Hemmung durch Amytal (Grenzwert $=66 \%$ ) und die Konzentration für halbmaximalen Effekt ist eingetragen

Anoxie). Die Extrapolation auf den Grenzwert wurde oben beschrieben (s. Abb. 3). Die Konzentrationen für halbmaximalen Effekt in Spalte 3 und 5 beschreiben die Sensibilität von Atmung und Fluoreszenz gegenüber den einzelnen Barbituraten. Einzelwerte aus den Titrationen der Gewebsatmung sind in Abbildung 9 zusammen mit der aus Abbildung 3 ermittelten Titrationskurve für Amytal aufgetragen. Diese Figur macht Übereinstimmungen und Unterschiede zwischen den einzelnen Barbituraten deutlich.

Aus der Reihe der untersuchten Barbiturate läßt sich eine Gruppe mit ähnlicher Seitenkette zusammenfassen: Amytal, Nembutal und Pentothal, die sämtlich an CAtom 5 des Barbitursäuregerüstes durch einen Äthylrest und einen aliphatischen Rest aus 5 C-Atomen (1-MethylButyl, bzw. 3-Methyl-Butyl) substituiert sind. Die Atmung zeigt ihnen gegenüber eine gleich hohe Sensibilität. Auch der Anteil der hemmbaren Atmung stimmt gut überein. Abweichungen der Mittelwerte liegen im Fehlerbereich der Einzelmessungen. Hinsichtlich der Hemmung mitochondrialer Funktionen stellt diese Gruppe die wirksamsten Verbindungen unter den hier untersuchten Barbituraten dar. Veronal mit 2 Äthylresten zeigt einen ausgesprochen geringen Effekt. Offensichtlich begünstigt eine längere aliphatische Seitenkette die Affinität zum Sitz der Hemmung im System der Atmungskette. Eine Übereinstimmung besteht auch zwischen Evipan und Luminal, die beide durch einen 6-atomigen Kohlenstoffring an C-Atom 5 substituiert sind, einfach ungesättigt bei Evipan, aromatisch bei Luminal. Für die Atmungshemmung scheint die in pharmakologischer Hinsicht wichtige Methylierung am $\mathrm{N}$-Atom 1 ohne Bedeutung zu sein.

Die klinisch wichtigsten Barbiturate dieser Reihe sind die Narkotika Evipan und Pentothal, von denen sich das Pentothal als die entschieden wirksamere Substanz erweist. Während bei maximaler Konzentration (d. h. über $3 \mathrm{mM}$ ) Evipan die Leberatmung auf weniger als die Hälfte reduziert, hemmt Pentothal zwei Drittel der Ausgangsatmung. Hinzu kommt noch eine deutlich geringere Sensibilität der Atmung gegenüber Evipan. Daraus resultiert, daß bei einer Konzentration von $0,8 \mathrm{mM}$ in der Perfusionslösung die Atmung der Rattenleber durch Evipan zu 20\%, durch Pentothal jedoch zu mehr als 50\% gehemmt ist. Im Tierversuch wird bei Barbituratnarkosen diese Konzentration im Serum erreicht (45). Evipan und Pentothal unterscheiden sich im Perfusionsexperiment auch hinsichtlich ihrer Auswaschbarkeit aus der Leber. Der Evipaneffekt ist fast ebenso rasch reversibel wie der des Amytals (s. Tab. 1). Die Atmungshemmung durch Pentothal dagegen wird auch nach längerem Auswaschen nur zu einem geringen Teil aufgehoben.

Eine ähnliche Übereinstimmung zwischen Molekülstruktur und Wirkung, wie wir sie für die Atmungshemmung diskutiert haben, besteht nicht für die Fluoreszenzänderungen. Abbildung 9 demonstriert die unter- 


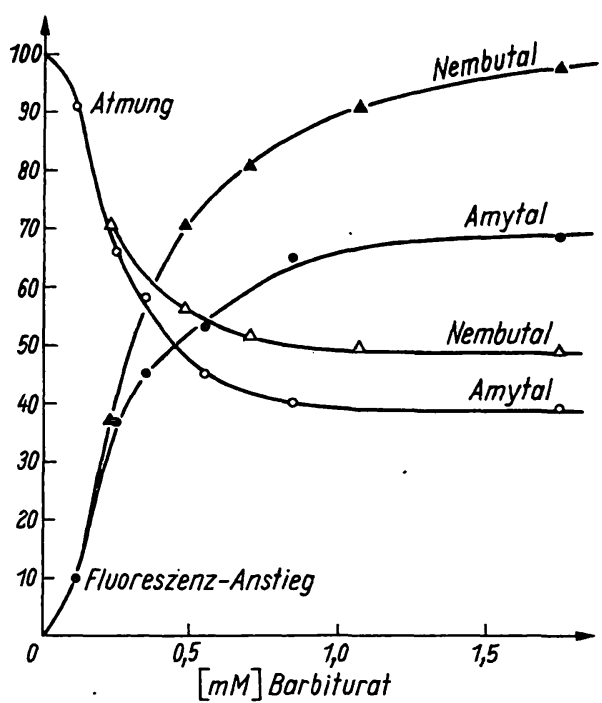

Abb. 10

Titrationskurven für Atmungshemmung und Fluoreszenzanstieg durch Amytal $(\mathrm{O}, \bullet)$ und Nembutal $(\Delta, \boldsymbol{\Delta})$ im Perfusionsexperiment Nr. 61.

Amytaltitration (120-130 Min. Perfusion): Ausgangsatmung 240,

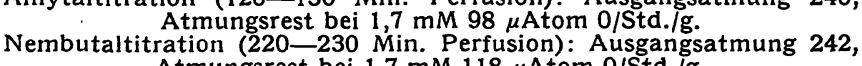

Atmungsrest bei $1,7 \mathrm{mM} 118 \mu \mathrm{Atom} 0 / \mathrm{Std}$./g.
Atmungshemmung bezogen auf Ausgangsatmung (= Fluoreszenzanstieg bezogen auf Anstieg nach 4 Min. Anoxie $(=100)$. Jeweils $40 \mathrm{Min}$. vor den Titrationen wurde ein Anoxie-Cyclus durchgeführt.

schiedlichen Effekte von Nembutal und Amytal, die sich bezüglich ihrer Struktur nur durch die Stellung der Methylgruppe im Pentylrest unterscheiden. In diesem Experiment wurde zunächst eine Amytaltitration und nach Auswaschen und vollständiger Restitution eine entsprechende Titration mit Nembutal durchgeführt. Die Atmungshemmung durch Nembutal ist geringer, der Fluoreszenzanstieg jedoch wesentlich stärker als der nach Amytal. Bei Nembutalkonzentrationen über 1,5 $\mathrm{mM}$ wird die Höhe der Anoxiefluoreszenz erreicht. Eine Erklärung für diesen Befund können wir nicht geben.

Einen paradoxen Effekt beobachten wir bei den Titrationen mit dem Thiobarbiturat Pentothal. Geringe Konzentrationen in der Perfusionslösung senken die Fluoreszenz bei gleichzeitiger Atmungshemmung. Der Fluoreszenzanstieg, der bei Konzentrationen um 0,5 mM einsetzt, bildet sich bei höheren Konzentrationen wieder zurück. Entgegen den Beobachtungen an anderen Barbituraten steigt die Fluoreszenz nach Auswaschen wieder an und stellt sich auf ein Niveau ein, das deutlich über der Ausgangsfluoreszenz liegt. Nach Zugabe von Pentothal bei ausgedehnter Anoxie wird ebenfalls eine Fluoreszenzsenkung gesehen. Pentothal ist eine schwach gelbliche Substanz. Eine Beeinflussung der Fluoreszenz infolge Absorption der erregenden und emittierten Strahlung - wie wir.sie für Hämoglobin diskutiert haben (20) - ist nicht ausgeschlossen, jedoch unwahrscheinlich für geringe Konzentrationen. Möglicherweise ist hier ein entkoppelnder Effekt auf die oxydative Phosphorylierung beteiligt, der für Pentothal und andere Thiobarbiturate neben ihrer Hemmwirkung auf die Atmung beschrieben wird $(14,16)$. Estabroor $(40)$ beobachtete, daß die Fluoreszenzintensität des mitochondrialen DPNH vom Zustand der energetischen Kopplung der Atmungskette abhängt. Er fordert ein energiereiches Zwischenprodukt $\mathrm{DPNH} \sim \mathrm{I}$, das für das sog. "fluorescence enbancement" verantwortlich sein soll. Wird dieses Zwischenprodukt zerstört, z. B. durch Zugabe von entkoppelnden Substanzen oder Überführung der Mitochondrien aus dem kontrollierten (, state 4") in den unkontrollierten Zustand (,state 3" nach CHANCE $(30,31))$, dann sinkt die Fluoreszenzausbeute ohne entsprechendes Absinken des DPNH-Spiegels. Den oben erwähnten Pentothaleffekt auf die Anoxiefluoreszenz beschreibt EsTABRooK für den Entkoppler Dinitrophenol, der einer Mitochondriensuspension unter anaeroben Bedingungen zugegeben wurde. Die bereits für Mitochondrien beschriebene komplexe Wirkung der Thiobarbiturate auf das System der Atmungskette wird in den Experimenten an der perfundierten Leber bestätigt.

Wir danken Frau Ursula Neumann, Frau Stefanie Schnitger; Frau Rosemarie Speckie und Fräulein Hanne Stanek für ihre umsichtige und tatkräftige Mitarbeit. Die Versuche unter Glukonèògenesebedingungen wurden in Zusammenarbeit mit Herrn cand. med. JÜRGEN ZEHNER durchgeführt.

Diese Arbeit wurde unterstützt von der Deutschen Forschungsgemeinschaft, det Fa. C. F. Boehringer u. Soehne GmbH, Mannheim, der Fa. KNoll A.G., Ludwigshafen, und der Fa. Dr. Karl Thomae GmbH, Biberach.

\section{Literatur}

1. Quastel, J. H. und A. H. M. Wheatley, Proc. Roy. Soc. B. 112, 60 (1932). - 2. Tatum, A. L., Physiol. Rev. 19, 472 (1939). 3. Butler, T. C., Pharmacol. Rev. 2, 121 (1950). - 4. QuAstel, J. H., Current Res. Anesthesia Analgesia 31, 151 (1952). - 5. Erler, J. J. und W. K. McEwen, Arch. Biochemistry 20, 163 (1949). - 6. Brody, J. M. und J. A. BaIn, Proc. Soc. exp. Biol. Med. 77, 50 (1951). - 7. BaIN, J. A., Federat. Proc. 11, 653 (195̆2). - 8. Brody, J. M. und J. A. BAIN, J. Pharmacol. exp. Therapeut. 110, 148 (1954). - 9. ERnster, L., O. JaLling, M. Löw und O. Lindberg, Exp. Cell Res. Suppl. 3, 124 (1955). - 10. ERNSTER, L., H. Löw und O. Lindberg, Acta chem. scand. 9, 200 (1955). 11. ChiAnce, B. und O. H. Gaebler, Enzymes, units of biological structure and function, S. 447, Academic Press, New York (1956). -12. Estabrook, R. W. und B. Mackler, J. biol. Chemistry 229, 1091 (1957). - 13. Hatefi, Y., R. C. Lester, F. L. Crane und C. WIDMER, Biochim. biophysica Acta (Amsterdam) 31, 490 (1959). - 14. Aldridge, W. N. und V. H. Parker, Biochem. J. 76, 47
(1960). - 15. Aldridge, W. N., Ciba Foundation Symposion (Enzymes and Drug Action) S. 155 (1962). - 16. Chance, B. und G. Hollunger, J. biol. Chemistry 278, 418 (1963). - 17. PumphREY, A. M. und E. R. REDfEarn, Biochim. biophysica Acta (Amsterdam) 74, 317 (1963). - 18. ERnster, L., G. Dallner und G. F. Azzone, J. biol. Chemistry 238, 1124 (1963). - 19. Chance, B. und B. Hess, J. biol. Chemistry 234, 2404 (1959). - 20. SchnitGer, H., R. Scholz, Th. Bücher und D. W. Lübbers, Biochem. Z. 341, 334 (1965). - 21. LübBers, D. W., M. Kessler, R. ScholZ und Th. Bücher, Biochem. Z. 341, 346 (1965). - 22. ScholZ, R. und Thr. Bücher, in: B. Chance, Control of Energy Metabolism, S. 393, Academic Press, New York (1965). - 23. Schrmassek, H. und W. GeroK, Biochem. Z. 343, 407 (1965). - 24. Chance, B. und F. F. JöBsis, Nature (London) 184, 195 (1959). — 25. LüBBERS, D. W., Pflügers Arch. ges. Physiol. Menschen. Tiere 265, 172 (1957). - 26. Gleichmann, U. und D. W. Lübbers, Plügers Arch. ges. Physiol. Menschen Tiere 271, 431 (1960). - 27. KIrSren, E., 
C. Gerez und R. KIRSten, Biochem. Z. 337, 312 (1963). - 28. Sachseṇmaier, W., persönliche Mitteilung. - 29. Hepp, D., E. Prüsse, H. Weiss und O. Wieland, Biochem. Z. 344, 87 (1966). -30. Chance, B. und G. R. Williams, J. biol. Chemistry 217, 409 (1955). - 31. Chance, B. und G. R. Williams, Advances in Enzymol. 17, 65 (1956). - 32. KLINGENBERG, M. W. SLenCZKA und E. RitT, Biochem. Z. 332, 47 (1959). - 33. KLINGenberg, M., persönliche Mitteilung. - 34. Bode, Cir. und M. KLINGEnBERG, Biochem. Z. 341, 271 (1965). - 35. BüCHER, TH und W. Rüssmann, Angew. Chem. Ausg. A (internat.) 3, 426 (1964). - 36. Chance, B., P. Cohen, F. F. Jöbsis und B. Schoener, Science (Washington) 136, 325 (1962). - 37. ChinCE, B., F. F. Jöbsrs, P. Colien und B. Schoener, Science (Washington) 137, 499 (1962).
-38. Chance, B. und B. Schoener, in: Symposium on Regulation of Enzyme Activity and Synthesis in Normal and Neoplastic Liver, S. 169, Indianapolis, October 1962, Pergamon Press, New York (1963). - 39. Chance, B., J. R. Williamson, D. Jamieson und B. Schoener, Biochem. Z. 341, 357 (1965). - 40. Estabrook, R. W. und S. P. Nissler, in: Funktionelle und morphologische Organisation der Zelle, S. 119, Springer-Verlag, Berlin-Göttingen-Heidelberg (1962). - 41. BüCHER, TH. und M. KLINGENberg, Angew. Chem. Ausg. A 70, 552 (1958). - 42. Petre, D., Naturwissenschaften 52, 597 (1965). - 43. ScFinaASSEK, H., Biochem. Z. 336, 460 (1963). - 44. HoforST, H. J., F. H. KREUTZ und Th. Bücher, Biochem. Z. 332, 18 (1959). - 45. Sproegel, E., Dissertation Med. Fak., Marburg/L. (1962).

\title{
Die Jod ${ }^{131}$-Markierung von Insulin, ACTH und STH mit hoher spezifischer Aktivität zur Anwendung in der radioimmunologischen Methode ${ }^{1}$ )
}

\author{
Von F. Melani2), K. M. Bartelt, R. Conrads und E. F. Pfeiffer \\ Aus der Abteilung für Klinische Endokrinologie (Leiter: Prof. Dr. E. F. Pfeiffer) der I. Medizinischen Universitätsklinik \\ Frankfurt an Main (Direktor: Prof. Dr. F. Hoff)
}

(Eingegangen am 23. August 1965)

\begin{abstract}
Für die Markierung von Insulin, ACTH und STH mit J ${ }^{131}$ wurden $\mathrm{Na} \mathrm{J}^{131}$ und Chloramin $\mathrm{T}$ als Oxydationsmittel benutzt. Mit dieser Methode läßt sich eine spezifische Radioaktivität von etwa $300-500 \mathrm{mC} / \mathrm{mg}$ erreichen. Nach der Markierung enthalten die Jod ${ }^{131}$-Hormonpräparationen $10-25 \%$ unspezifische Radioaktivität. Die Degradationsprodukte wurden an Serumproteine adsorbiert und auf „Sephadex“c-Säulen von Hormon-Jod ${ }^{131}$ getrennt. Nach zwei Reinigungen lag die unspezifische Radioaktivität bei Insulin- $\mathrm{J}^{131}$ und ACTH-J131 stets unter $5-6 \%$, während sie bei STH-J131 immer wesentlich höher war. - Es wurde niemals eine Bindung des intakten Insulin-J131- und ACTH$\mathrm{J}^{131}$-Moleküls an Serumproteine beobachtet. Beim STH konnte hingegen nicht mit Sicherheit entschieden werden, ob das intakte STH-J131-Molekül an Serumproteine gebunden wird oder nicht.

Die Möglichkeiten und Grenzen der radioimmunologischen Bestimmung von Eiweißhormonen im Blut werden aufgeführt.

$\mathrm{NaI}^{131}$ and chloramine $\mathrm{T}$ were used as oxidising agents for labelling insulin, ACTH and STH with $\mathrm{I}^{131}$. A specific radioactivity of about $300-500 \mathrm{mC} / \mathrm{mg}$ was obtained with this method. After labelling, the $\mathrm{I}^{131}$-hormone preparations contain $10-25 \%$ of unspecific radioactivity. The degradation products were adsorbed onto serum proteins and separated from hormone-I ${ }^{131}$ on "Sephadex" columns. After two purifications, the unspecific radioactivity with insulin- $-^{131}$ and ACTH-I ${ }^{131}$ was always below $5-6 \%$, but it was always essentially higher with STH- ${ }^{131}$. Binding of the intact insulin- $\mathrm{I}^{131}$ and $\mathrm{ACTH}-\mathrm{I}^{131}$ molecules to serum protein was never observed. It is not certain, however, whether the STH-I'131 molecule is bound to serum protein or not.

The possibilities and limits of the radio-immunological determination of protein hormones in blood are discussed.
\end{abstract}

Die wegen ihrer Empfindlichkeit und Genauigkeit geschätzten radioimmunologischen Verfahren zur Bestimmung von Hormonen im Blut haben in den letzten Jahren weite Verbreitung gefunden. Wenn sich die verschiedenen Methoden in der Technik auch beträchtlich unterscheiden, bauen sie doch alle auf dem gleichen Prinzip auf, das von YaLOW und Berson (1) erstmalig für die Bestimmung von Insulin im Blut nutzbar gemacht worden ist: in einer Gleichgewichtsreaktion wird Jod ${ }^{131}$-markiertes und nicht markiertes Hormon von spezifischen Antikörpern kompetitiv gebunden. In einem System, in dem die Konzentration der Antikörper und des Jod ${ }^{131}$-markierten Hormones konstant und die Konzentration des nicht markierten Hormones variabel gehalten werden, ịst dạs Verhältnis von anțikörperge-

1) Durchgeführt mit Unterstützung der Deutșchen Forschungsgemeinschaft, Bad Godesberg.

2) Stipendiat der Alexander-von-Humboldt-Stiftung 1963/65. bundenem (B) und freiem (F) Jod ${ }^{131}$-Hormon eine Funktion des nicht markierten Hormones.

Die zur Ermittlung des Quotienten B/F erforderliche Trennung von antikörpergebundenem und freiem Hormon kann auf verschiedene Weise bewerkstelligt werden: mit der Papierelektrophorese $(1,2)$, durch Fällung des Antigen-Antikörperkomplexes mit Natriumsulfat (3) oder mit einem gegen den hormonspezifischen Antikörper gerichteten zweiten Antikörper (4, 5, 6). Einige dieser Techniken $(7,1,2)$ sind auf Jod ${ }^{131}$-Hormonpräparate mit hoher spezifischer Radioaktivität angewiesen, während andere $(3,4,5)$ mit niedrig markierten Hormonen auskommen. In jedem Fall aber erlaubt die Verwendung von hoch markierten Hormonen, die Konzentration des Tracers klein zu halten und damit die Empfindlichkeit der Methode zu erhöhen.

Eine weitere Technik bedient sich des Anionenaustauschers zur Trennung von antikörpergebundenem und 